\title{
Digital Pressure Meter Tensimeter Dan Suction Pump
}

\author{
Mukhamad Ryan Nur Rokhman, Bambang Guruh Irianto, Her Gumiwang Ariswati \\ Jurusan Teknik Elektromedik Politeknik Kesehatan Kemenkes, Surabaya \\ Jl. Pucang East Jajar No. 10, Surabaya, 60245, Indonesia \\ ryannrokhman@gmail.com, BGI_DHA@poltekkesdepkes-sby.ac.id, hergum@poltekkesdepkes-sby.ac.id
}

\begin{abstract}
Abstrak -- Kalibrasi merupakan suatu kegiatan teknis yang terdiri atas penetapan, penentuan satu atau lebih sifat dan karakteristik dari suatu produk, proses atau jasa sesuai dengan prosedur khusus yang telah ditetapkan. Tujuan kalibrasi yaitu untuk menjamin hasil pengukuran sesuai dengan standar nasional maupun internasional. Digital pressure meter (DPM) Tensimeter dan Suction Pump merupakan alat kalibrasi yang digunakan untuk menentukan tekanan positif maupun negatif (vacum). Memiliki titik resolusi naik turun $0,25 \mathrm{mmHg}$. Display yang digunakan pada modul ini adalah LCD 4x20 dimana pemrograman keseluruhan menggunakan arduino ATmega328. Setelah melalui proses pembandingan dengan alat Pressure Calibrator di BPFK yang terkalibrasi di dapat nilai kesalahan dan error cukup rendah untuk nilai kesalahan pada tekanan positif bernilai kurang dari $0,83 \mathrm{mmHg}$, dan kurang dari 0,67 untuk tekanan negatif. Memiliki hasil rata-rata error sebesar 0,24\% untuk tekanan positif dan tekanan negatif.
\end{abstract}

Kata Kunci: Kalibrasi, Tekanan Positif, Tekanan Negatif

\section{PENDAHULUAN}

Setiap alat kesehatan yang digunakan di fasilitas pelayanan kesehatan dan fasilitas kesehatan lainnya harus dilakukan uji dan atau kalibrasi secara berkala oleh balai pengujian fasilitas kesehatan atau institusi pengujian fasilitas kesehatan. Kalibrasi adalah kegiatan peneraan untuk menentukan kebenaran nilai penunjukan alat ukur dan atau bahan ukur [1].

Pengukuran tekanan darah merupakan komponen penting dari pemeriksaan umum setiap pasien dan sphygmomanometer adalah salah satu peralatan medis diagnostik yang paling umum digunakan. Pengukuran tekanan darah yang akurat membutuhkan penggunaan suatu sphygmomanometer akurat. Sebuah sphygmomanometer manual alat yang digunakan untuk mengukur tekanan darah, dan terdiri dari tiup manset, manometer merkuri (atau pengukur aneroid) dan bola inflasi dan pengukur. Manset tiup digunakan untuk membatasi aliran darah, dan manometer digunakan untuk mengukur tekanan. Keakuratan dari sphygmomanometer sangat bergantung pada melakukan perawatan yang benar dan proses kalibrasi peralatan ini. Salah satu kesalahan paling umum dalam pengukuran tekanan darah disebabkan dengan menggunakan sphygmomanometer tidak terkalibrasi dan penggunaan manset yang kurang tepat. Pemeliharaan dan kalibrasi sphygmomano meter yang tidak adekuat adalah penyebab kesalahan sistematis dalam pengukuran tekanan darah[2].

Salah satu alat kalibrator adalah DPM (Digital Pressure Meter). DPM merupakan alat yang digunakan untuk mengukur tekanan positif dan negatif dari alat kesehatan dalam bentuk baik cair atau gas untuk membantu dalam perbaikan dan kontrol kualitas. Dalam hal ini, DPM digunakan untuk melakukan kalibrasi pada tensimeter air raksa dan suction pump.

Alat ini banyak sekali di pasaran, salah satu mahasiswa teknik elektromedik yang membuat tugas akhir dengan judul Portable Kalibrator Tensimeter Berbasis Mikrokontroller ATmega 8535 adalah Heru Wahyu Purnama (2014)[3]. Pada alat yang dibuat ini mengangkat konsep tekanan positif (Positive Pressure) untuk satu tipe tensimeter air raksa saja dengan ditampilkan pada LCD karakter, tetapi alat ini tidak dilengkapi dengan tekanan hisap (Vacum pressure). Pada tahun 2017 Junia Dyah Permata Wibisono membuat tugas akhir dengan judul Digital Pressure Meter (DPM) Vacum Pressure dengan tampilan LCD karakter[4]. Pada alat ini hanya menggunakan 1 (satu) mode saja yang digunakan hanya untuk suction pump. Pada Tahun 2018 Yosep Kurniawan membuat tugas akhir tentang Digital Pressure Meter (DPM) dua mode yaitu tekanan positive dan tekanan hisap namun alat ini tingkat keakurasiannya masih relative standart[5].

Berdasarkan hasil telusur masalah diatas, untuk efektivitas maka dibuatlah DPM Tensimeter dan Suction Pump untuk meningkatkan nilai keakurasian alat kalibrator tersebut.

\section{BAHAN DAN METODE}

\section{A. Rancangan penelitian}

Penelitian ini menggunakan alat Pressure Calibrator Merk Crystal Engineering Corporation sebagai kalibrator dengan setting tekanan positif $0 \mathrm{mmHg}, 50 \mathrm{mmHg}, 100 \mathrm{mmHg}$, $150 \mathrm{mmHg}, \quad 200 \mathrm{mmHg}, \quad 250 \mathrm{mmHg}, \quad 300 \mathrm{mmHg}$. Setting tekanan negatif $-0 \mathrm{mmHg},-50 \mathrm{mmHg},-100 \mathrm{mmHg},-150 \mathrm{mmHg}$, $-200 \mathrm{mmHg}, \quad-250 \mathrm{mmHg}, \quad-300 \mathrm{mmHg}, \quad-350 \mathrm{mmHg}, \quad-$ $400 \mathrm{mmHg}$.

\section{1) Alat dan Bahan}

Penelitian ini menggunakan alat Pressure Calibrator Merk Crystal Engineering Corporation sebagai pembanding yang berada di BPFK. Sensor MPX5050GP berfungsi sebagai 
pendeteksi tekanan positif. Sensor MPXV4115U berfungsi sebagai pendeteksi tekanan negatif. Output sensor tersebut masuk pada pin analog pada mikrokontroller. Arduino Atmega 328 sebagai pengontrol dan pengendali. Output Atmega 328 berupa tampilan pada display LCD character $4 \times 20$.

\section{2) Percobaan}

Dalam studi ini, setelah desain jadi, dilakukan pengujian hasil pengukuran tekanan pada modul dan pembanding dengan tekanan maksimal positif $300 \mathrm{mmHg}$ dan tekanan maksimal negatif $-400 \mathrm{mmHg}$. Setiap titik tekanan, nilai hasil dihitung untuk menvalidasi hasil penelitian ini.

\section{B. Diagram Blok}

Sensor MPX5050 berfungsi sebagai pembacaan tekanan positif atau positive pressure untuk mengkalibrasi alat tensimeter. Sensor MPXV41115U berfungsi sebagai pembacaan tekanan negatif atau vacum pressure untuk mengkalibrasi alat Suction Pump. Mikrokontroller berfungsi untuk pengolahan data dari sensor, dan display hasil pengolahan mikrokontroller ditampilkan pada LCD character.

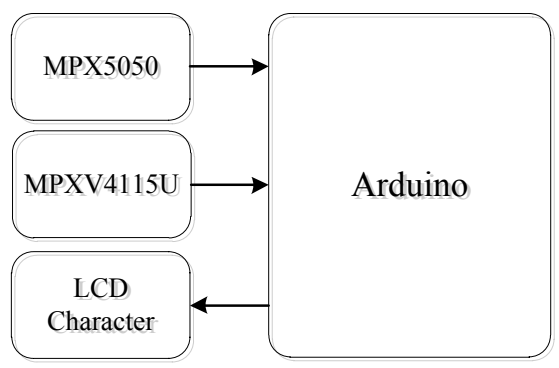

Gambar 1. Diagram Blok Modul

\section{Diagram Alir}

Saat start mikrokontroller akan melakukan inisialisasi program dan pembacaan ADC. Setelah memilih tekanan positif/vacum, kemudian mikrokontroller akan melakukan pembacaan ADC sesuai dengan tekanan yang masuk pada PIN Analog. Mikrokontroller akan mengkonversi rumus tekanan dari $\mathrm{kPa}$ menjadi mmHg. Hasil pengolahan data pada mikrokontroller akan ditampilkan pada LCD character.

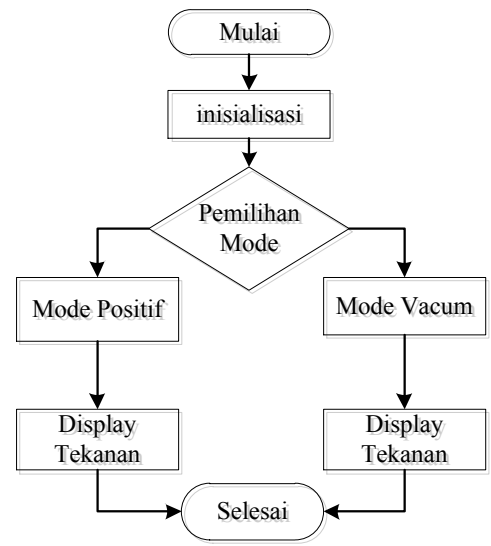

Gambar 2. Diagram Alir Proses

\section{Skematik rangkaian}

Hal yang terpenting dari pembuatan modul adalah skematik rangakaian. Skematik ini berfungsi sebagai pengolaan data. Data akan di olah pada arduino Atmega328

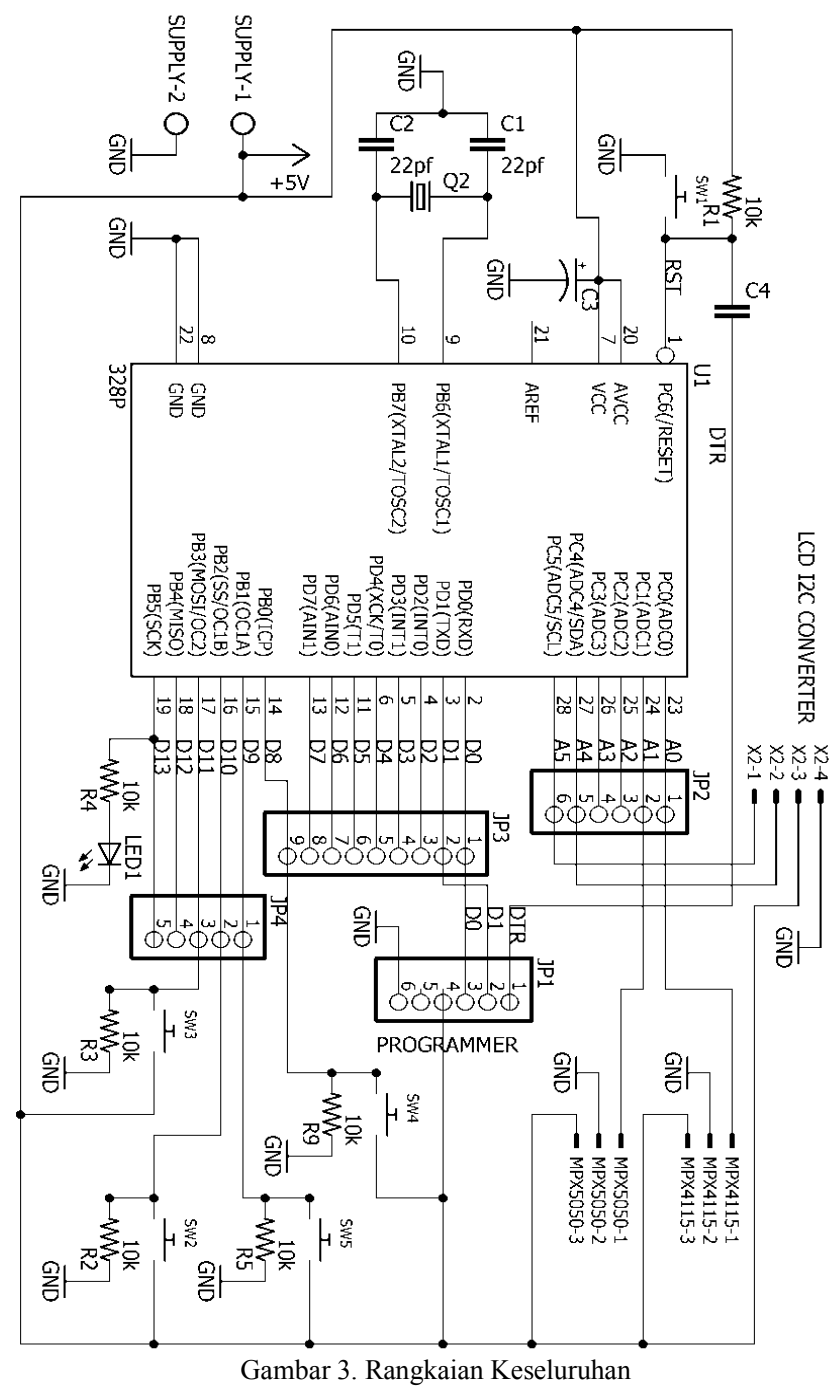




\section{HASIL}

Dalam penelitian ini, DPM tensimeter dan Suction pump layak digunakan untuk mengkalibrasi tensimeter dan suction pump karena hasi penelitian masih dalam batas tooleransi.

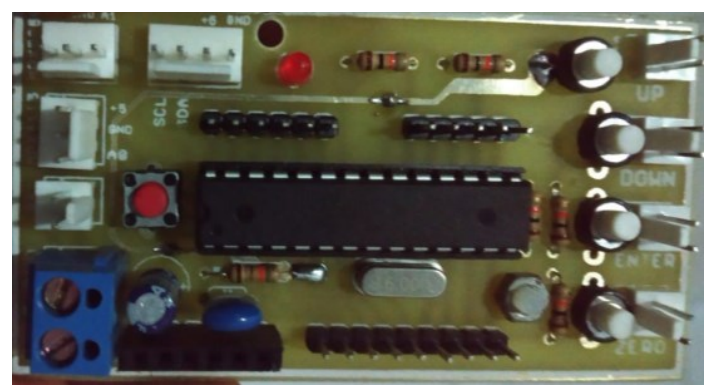

Gambar 4. Desain mikrokontroller
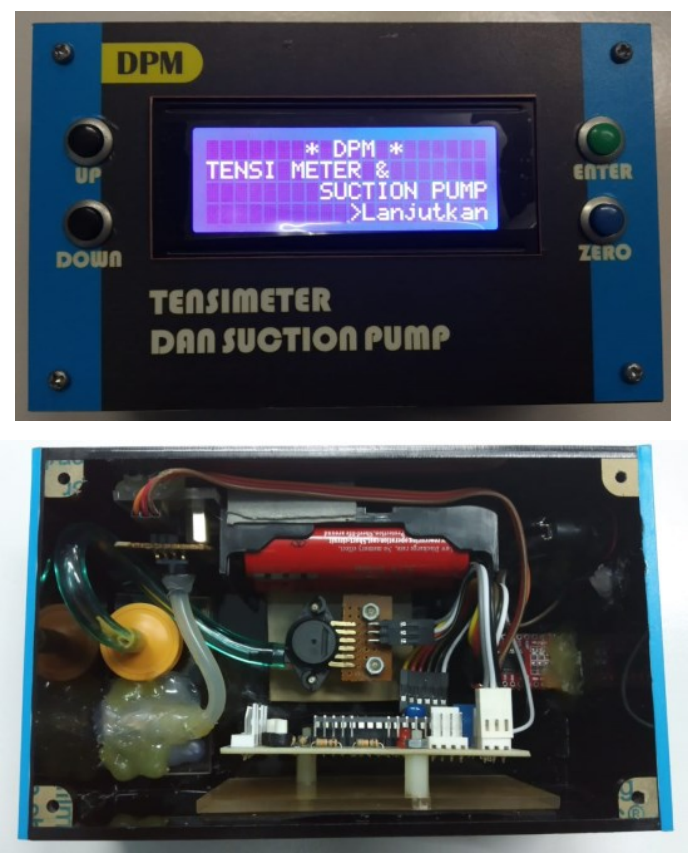

Gambar 5. Desain dan tampilan modul

\section{1) Listing Program}

Pada program ini adalah pembacaan sensor MPX5050 untuk mendeteksi tekanan positif dan masuk pada PIN ADC 1 pada mikrokontroller dan konversi tekanan $\mathrm{kPa}$ ke $\mathrm{mmHg}$.

void tekananpositif()

\{

int positif $=$ analogRead(TEKANANPOSITIF $)$;

float teganganpositif $=($ positif*5.0/1023.0 $) * 1000$;

float $\mathrm{kpaP}=($ teganganpositif-teganganP $) / 90$;

$\operatorname{mmhgP}=(\mathrm{kpaP} * 7.50062)-$ zeroP;
Pada program ini adalah pembacaan sensor MPXV4115 untuk mendeteksi tekanan negatif dan masuk pada PIN ADC 0 pada mikrokontroller dan konversi tekanan $\mathrm{kPa} k \mathrm{mmHg}$.

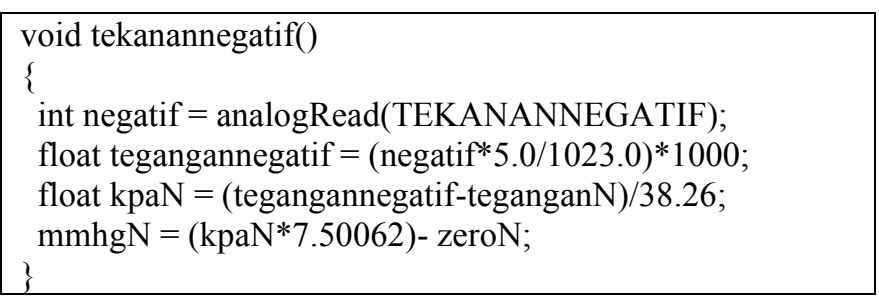

\section{2) Data pengukuran output Sensor}

Dari data tabel 1 merupakan data error pada tekanan positif. Nilai error tertinggi pada titik akurasi $100 \mathrm{mmHg}$ dengan nilai error $0,59 \%$. Dan nilai error terendah pada titik akurasi $300 \mathrm{mmHg}$ dengan nilai error $0,08 \%$.

TABle i. Hasil Pengolahan Data ERror ( \% ) Pada Pengukuran TEKANAN POSITIF

\begin{tabular}{cc}
\hline $\begin{array}{c}\text { Titik Akurasi } \\
(\mathrm{mmHg})\end{array}$ & Error ( \% ) \\
\hline 0 & 0,25 \\
\hline 50 & 0,24 \\
\hline 100 & 0,59 \\
\hline 150 & 0,31 \\
\hline 200 & 0,12 \\
\hline 250 & 0,12 \\
\hline 300 & 0,08 \\
\hline
\end{tabular}

Dari data tabel 2 merupakan data error pada tekanan negatif. Nilai error tertinggi pada titik akurasi -200 mmHg dengan nilai error $0,77 \%$. Dan nilai error terendah pada titik akurasi -300 $\mathrm{mmHg}$ dengan nilai error $0,01 \%$.

TABle II. Hasil Pengolahan Data Error ( \% ) Pada Pengukuran TEKANAN NEGATIF

Titik Akurasi

Error $(\%)$

\begin{tabular}{cc}
\hline 0 & 0,16 \\
\hline-50 & 0,09 \\
\hline-100 & 0,77 \\
\hline-150 & 0,04 \\
\hline-200 & 0,56 \\
\hline-250 & 0,41 \\
\hline-300 & 0,01 \\
\hline-350 & 0,02 \\
\hline-400 & 0,10 \\
\hline
\end{tabular}




\section{PEMBAHASAN}

Untuk mengetahui tingkat presisi pada modul, kita harus membandingkan modul ini dengan pembanding yang lebih akurat dan terkalibrasi. Disini penulis menggunakan Pressure Calibrator merk Crystal Engineering Corporation sebagai kalibrator untuk mengetahui seberapa besarkah akurasi dan presisi dari alat tersebut.

Pada titik setting $0 \mathrm{mmHg}, 50 \mathrm{mmHg}, 100 \mathrm{mmHg}$, $150 \mathrm{mmHg}, 200 \mathrm{mmHg}, 250 \mathrm{mmHg}, 300 \mathrm{mmHg}$ pada tekanan positif dilakukan pembandingan sebanyak 3 kali pengukuran. Data error pada tekanan positif, Nilai error tertinggi pada titik akurasi $100 \mathrm{mmHg}$ dengan nilai error $0,59 \%$. Dan nilai error terendah pada titik akurasi $300 \mathrm{mmHg}$ dengan nilai error $0,08 \%$.

Pada titik setting $-0 \mathrm{mmHg},-50 \mathrm{mmHg},-100 \mathrm{mmHg}$, $150 \mathrm{mmHg},-200 \mathrm{mmHg},-250 \mathrm{mmHg},-300 \mathrm{mmHg},-350 \mathrm{mmHg}$, $-400 \mathrm{mmHg}$ pada tekanan negatif dilakukan pembandingan sebanyak 3 kali pengukuran. Data error pada tekanan negatif, Nilai error tertinggi pada titik akurasi $-100 \mathrm{mmHg}$ dengan nilai error $0,77 \%$. Dan nilai error terendah pada titik akurasi -300 $\mathrm{mmHg}$ dengan nilai error $0,01 \%$.

\section{KESIMPULAN}

Dari hasil analisa yang dibuat dapat disimpulkan bahwa alat ini memiliki kelebihan dibandingkan penelitian - penelitian sebelumnya, diantaranya terdapat penamabahan tingkat ketelitian yaitu kenaikan $0,25 \mathrm{mmHg}$. Hasil perbandingan tekanan positif yakni tekanan 0 sampai $300 \mathrm{mmHg}$ merupakan pengukuran menggunakan Pressure Calibrator Merk Crystal Engineering Corporation sebagai kalibrator dan pengambilan data pembanding. Simpangan/ kesalahan data tertinggi pada titik akurasi $100 \mathrm{mmHg}$ dimana nilai simpangannya 0,83 $\mathrm{mmHg}$. Nilai error terendah pada titik akurasi $300 \mathrm{mmHg}$ dengan nilai error $0.08 \%$ dan nilai error tertinggi pada titik akurasi $100 \mathrm{mmHg}$ dengan nilai error 0,59\%.

Hasil pengukuran tekanan negatif yakni tekanan 0 sampai $400 \mathrm{mmHg}$ merupakan pengukuran menggunakan Pressure Calibrator Merk Crystal Engineering Corporation sebagai kalibrator dan pengambilan data pembanding. Simpangan/ kesalahan data tertinggi pada titik akurasi $-150 \mathrm{mmHg}$ dimana nilai simpangannya $0,67 \mathrm{mmHg}$. Nilai error terendah pada titik akurasi $-300 \mathrm{mmHg}$ dengan nilai error $0.01 \%$ dan nilai error tertinggi pada titik akurasi $100 \mathrm{mmHg}$ dengan nilai error $0,77 \%$. Nilai ketidakpastian pada modul masih relatif tinggi yaitu 0,51 pada tekanan positif dan 0,67 pada tekanan negatif.

\section{DAFTAR PUSTAKA}

[1] PERMENKES, “Permenkes No.54 Tahun 2015.” 2015.

[2] Direktorat jendral pelayanan medik, "Peraturan Menteri Kesehatan Nomor 363 Tahun 1998-Tentang Institusi Penguji Alat Kesehatan Buku Pedoman," pp. 6-7, 1998.
[3] T. Prilian, H. A. Pudji, S. T. Mt, and S. Mt, "Digital Pressure Meter Berbasis Arduino," Jurnal Teknoke,s pp. 1-10, 2014

[4] M. Junia Dyah Permata Wibisono, Priyambada Cahya Nugraha, MT, $\mathrm{Hj}$. Andjar Pudji, ST and ABSTRAK, "“ Digital Pressure Meter ( DPM ) Va cum Pressure,' Skripsi, Jur. Tek. Elektromedik Politek. Kesehat. KEMENTRIAN Kesehat. SURABAYA, 2017.

[5] S. T. Akhir, "Dpm dua mode Berbasis Mikrokontroller," Jurnal Teknokes, 2018. 